\title{
Interventions for body weight reduction in obese patients during short consultations: an open-label randomized controlled trial in the Japanese primary care setting
}

\author{
Satoshi Kanke ${ }^{1 *}$, Takumi Kawai ${ }^{1}$, Naomi Takasawa' ${ }^{1}$ Yukiko Mashiyama ${ }^{1}$, Atsushi Ishii ${ }^{2}$ and Ryuki Kassai ${ }^{1}$
}

\begin{abstract}
Background: Family physicians should maintain regular contact with obese patients to ensure they effectively reduce their body weight. However, family physicians in Japan have on average only 6 (min) per consultation, and conventional interventions for body weight reduction require a longer consultation or additional manpower. A brief intervention within the limited consultation time available is therefore needed. Here we investigated the effectiveness of a brief weight reduction intervention for obese patients and the related factors for reducing body weight during routine consultations in the primary care setting.

Method: We conducted an open-label randomized controlled trial at a family medicine clinic in Fukushima, Japan from January 2010 to June 2011. Patients aged 30 to 69 years with body mass index $\geq 25$ who were diagnosed with hypertension, dyslipidemia, and/or type 2 diabetes mellitus were randomly assigned to the intervention or control group. At every consultation, body weight in the intervention group was measured by a family physician who provided weight reduction advice in addition to usual care. The primary outcome was body weight change at 1 -year follow up. Analysis was done by intention to treat.
\end{abstract}

Result: We randomly assigned 29 participants to the intervention group and 21 to the control group. Forty participants $(80 \%)$ remained in the trial until the 1 -year follow up. At follow up, the median body weight change from baseline was not significantly different between the groups $(p=0.68$ ), at -0.8 (interquartile range [IQR] -2.5 to 1.0$) \mathrm{kg}$ in the intervention group and 0.2 (IQR -2.4 to 0.8$) \mathrm{kg}$ in the control group.

Conclusion: We devised an intervention method for physicians to measure body weight and advise on weight reduction during routine consultations. In our setting, this method did not extend the consultation time, but also had no significant additional effects on body weight reduction in moderately obese patients.

Trial registration: This trial is registered with the UMIN Clinical Trial Registry (UMIN000002967).

Keywords: Obesity, Weight reduction, Brief intervention, Primary care, Outpatient care, Short consultation

\section{Background}

The number of patients with hypertension, dyslipidemia, or type 2 diabetes mellitus has increased in the last few decades in Japan [1]. From 2002 to 2011, the number of patients with hypertension increased from 7 million to 9 million, those with dyslipidemia from 1.4 million to 1.9

\footnotetext{
* Correspondence: kanke@fmu.ac.jp

'Department of Community and Family Medicine, Fukushima Medical University, 1 Hikarigaoka, Fukushima City, Fukushima Prefecture, Japan Full list of author information is available at the end of the article
}

million, and those with type 2 diabetes from 2.3 million to 2.7 million [1]. All three of these diseases are related to obesity [2, 3]. In 2008, more than $10 \%$ of the world's adult population was obese according to the World Health Organization's definition of a body mass index $(\mathrm{BMI}) \geq 30 \mathrm{~kg} / \mathrm{m}^{2}$ [4], although only $3 \%$ of the Japanese population in 2011 conformed to this definition of obesity [5]. As the incidence rates of obesity-related diseases in Japan have been increasing, an international expert panel proposed a lower BMI cut-off for the Japanese

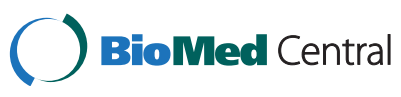

(c) 2015 Kanke et al.; licensee BioMed Central. This is an Open Access article distributed under the terms of the Creative Commons Attribution License (http://creativecommons.org/licenses/by/4.0), which permits unrestricted use, distribution, and reproduction in any medium, provided the original work is properly credited. The Creative Commons Public Domain Dedication waiver (http://creativecommons.org/publicdomain/zero/1.0/) applies to the data made available in this article unless otherwise stated. 
population [6]. The current definition of obesity for Japanese is $B M I \geq 25 \mathrm{~kg} / \mathrm{m}^{2}$ [7]. According to this definition, $30 \%$ of Japanese adult men and $21 \%$ of Japanese adult women were reported to be obese in 2011 [5]. Developing an effective intervention for reducing the body weight of obese Japanese patients has the potential to improve the management of obesity-related diseases.

Although the guidelines for managing overweight and obesity recommend advising patients with obesity-related diseases to lose weight [8], the weight reduction approach of healthcare providers remains inadequate [9]. Primary care physicians meet many obese patients with obesityrelated diseases [10] and should maintain regular contact with these patients to ensure they reduce their body weight as necessary. Epstein and Ogden revealed conflicting points of view between primary care physicians and obese patients. Obese patients regarded obesity as a medical problem that should be managed by the physicians. In contrast, physicians consider obesity management to be primarily the patient's responsibility. One of the reasons for this discord is the lack of effective patient interventions in the primary care setting [11]. In the primary care setting, physicians need a brief and easy-to-perform intervention method for encouraging obese patients to lose weight. Because physicians manage on average three problems during each short consultation [12], it is too difficult to provide the proven intervention methods established in other studies in a real-world clinical setting. In previous studies conducted in the primary care setting outside of Japan, patient body weight has been effectively reduced through lifestyle counseling provided by medical assistants, nurses, or dietitians [13-15], as well as by Internet-based intervention programs [16, 17]. In Japan, providing these interventions in the primary care setting is difficult because very few dietitians work for primary care clinics and clinic nurses do not have sufficient experience in lifestyle counseling. In fact, most lifestyle counseling is given by Japanese primary care physicians during regular patient visits [18]. In other studies, physicians have provided tailored intervention to obese patients during 15 to 20-min long consultations [19, 20]; however, in Japan, primary care consultations last for around $6 \mathrm{~min}$ [21], meaning that primary care physicians cannot practically provide any effective counseling-based interventions due to time constraints. In the Japanese primary care setting, physicians need simple and easy-to-perform methods of intervention that are suitable for use in routine brief consultations.

In our clinical experience, some of our obese patients, whose body weight was checked by the physician at every consultation, managed to reduce their body weight. Based on this success, we focused on body weight monitoring as an innovative method for promoting body weight reduction in the primary care setting. In general, weight reduction strategies consist of the following five approaches: dietary intervention, physical activity, behavioral treatment, pharmacotherapy, and surgical therapy [3]. Many studies in the primary care setting have reported the effects of dietary intervention, physical activity, and pharmacotherapy on body weight reduction in obese patients [13-15]. However, weight monitoring is a component of behavioral treatment, and in the area of behavioral treatment, most studies on body weight reduction have applied an intensive approach in an academic setting; few studies have reported the effects of behavioral treatment on body weight reduction in the primary care setting [22].

Against this background, we hypothesized that if physicians involved in outpatient care measure patient body weight and advise on weight reduction at every consultation, this approach might reduce the body weight of obese patients since it can be performed quickly and easily. There are several important points regarding the approach taken in this study. First, obese patients should monitor their weight with their physician since weight monitoring enables obese patients to recognize their actual condition. We planned weight monitoring with a physician at every consultation to ensure a sense of urgency and motivation for lifestyle change. Second, physicians should ask patients about their lifestyles based on the measured body weight and provide specific advice on aspects that are difficult to improve. Third, an intervention method for lifestyle change is needed to improve doctor-patient relationships [23, 24]. Fourth, we planned to establish a trust relationship by requesting the physician to advise on the intervention method. The objective of this study, therefore, was to devise a brief and easy-to-perform intervention method for body weight reduction in the Japanese primary care setting.

\section{Methods}

\section{Design and participants}

We planned an open-label randomized control study at a family medicine clinic (Date City, Fukushima Prefecture, Japan) attended by four family physicians. Date city is located $250 \mathrm{~km}$ north of Tokyo, its population was about 66,000 people in 2010 , and main industry of the city is agriculture. From January to June 2010, we checked the medical records of adult patients aged 30-69 years who visited the family medicine department for routine checkups for hypertension, dyslipidemia, and/or type 2 diabetes mellitus. A total of 180 patients were matched in January 2010. From the pool, we recruited 57 patients with a BMI $\geq 25 \mathrm{~kg} / \mathrm{m}^{2}$ (moderately to severely obese) to participate in this study. We excluded patients with a history of cancer or psychological disease, or those prescribed hormone therapy because these factors are known to affect body weight [25-27]. We informed all participants of the aim and content of the study, and obtained their written 
consent to participate. After being informed of this research project, 51 patients agreed to participate. One participant with a history of cancer was excluded. At baseline measurement, 50 participants (18 women, $36 \%$; 32 men, $64 \%$ ) were enrolled. We randomized 29 participants to the intervention group and 21 participants to the control group. In total, 44 participants $(88 \%)$ were assessed for body weight changes at 6 months, and 40 participants $(80 \%)$ remained in the study until the 1-year follow up (Fig. 1).

\section{Baseline data and measurement}

After the participants agreed to participate, their physician collected the following baseline data: age, sex, history of hypertension (yes or no), history of dyslipidemia (yes or no), history of type 2 diabetes (yes or no), educational background (junior high school, high school, technical college, or university), history of smoking (never smoker, former smoker, or current smoker), history of alcohol consumption (never drinker, <once a week, $<3$ times per week, $<6$ times per week, or daily), and frequency of body weight self-monitoring (<once a month, <once a week, several times per week, or daily).

Nurses, who were blinded to the group assignment of each patient, measured participant height, body weight, abdominal circumference, and blood pressure. After defecating and urinating, participants removed their shoes and wore as light clothing as possible for height and body weight measurement on a digital scale. Abdominal circumference was measured at the umbilical level with a tape measure in the standing position and at end-expiratory pressure [28], and blood pressure was measured in the sitting position with an automated sphygmomanometer after a few minutes rest. We checked these data and the participants' medical records to ensure the participants met the criteria for metabolic syndrome (Japanese criteria and the National Cholesterol Education Program-Adult Treatment Panel III criteria) $[28,29]$.

\section{Randomization}

Participants were assigned original identification numbers, which were sent to a co-researcher (AI) working at another hospital who randomized these numbers into two groups (intervention group and control group) by means of a table of random numbers. The randomization results were sent to the chief researcher (SK) who informed the participants. Figure 1 shows the participant flow throughout the study.

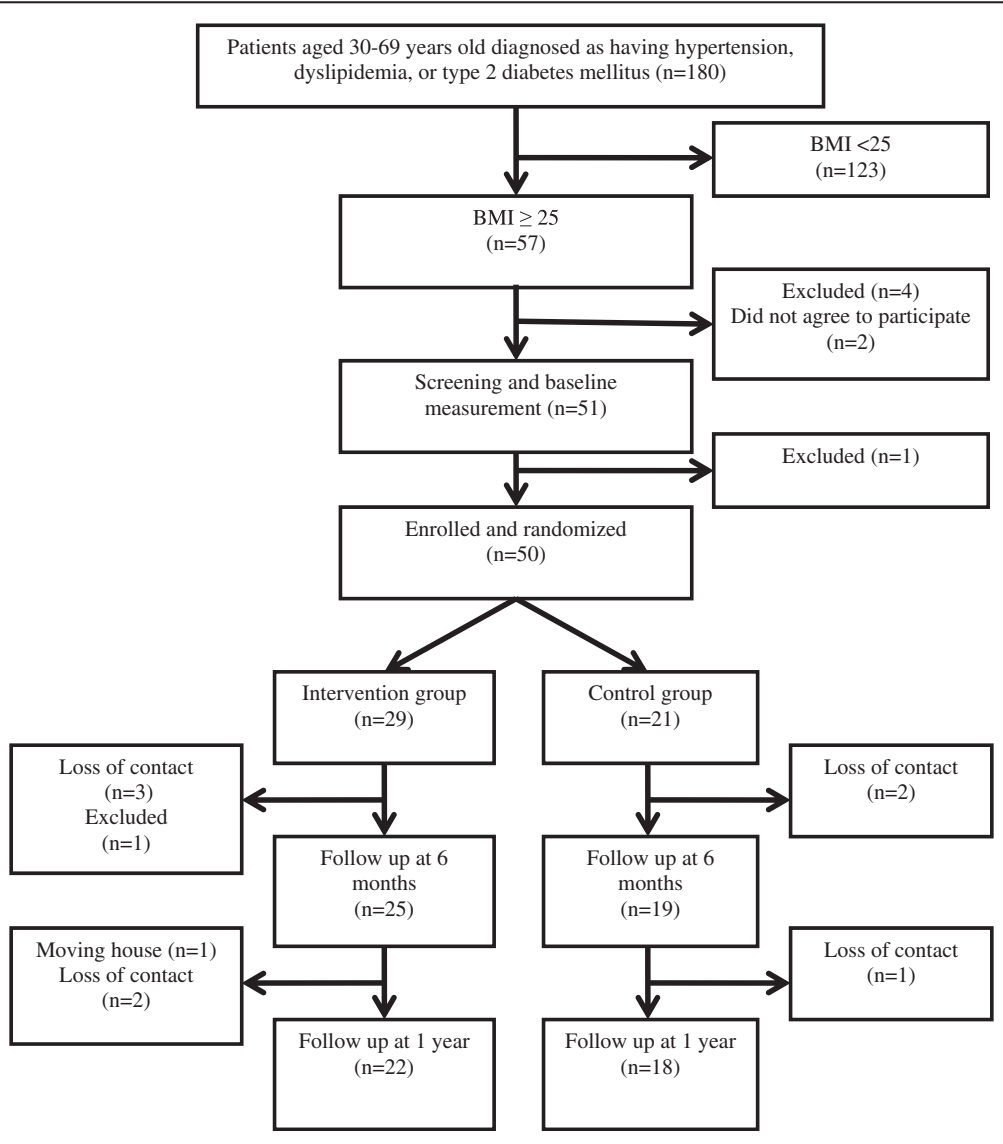

Fig. 1 Participant flow chart 


\section{Intervention}

In the intervention group, at the first consultation after randomization, participants were informed about their ideal body weight, weight reduction target (5\% of current weight), and the positive effect of weight reduction for their current diseases by the physician, who provided them with an information leaflet [30]. Participants were also informed that a physician would check their body weight and provide specific advice on weight reduction at every regular consultation. Thereafter, the participants received care for their current diseases based on the Japanese guidelines for hypertension, dyslipidemia, and type 2 diabetes [31-33] every 1 or 2 months. A physician measured body weight after defecation and micturition using an analogue scale at every consultation and provided advice in relation to the changes of measured body weight at each consultation. In addition, at every consultation, the physician was required to specifically question the patient on eating and exercise, to reconfirm the patient's weight target, and to provide advice focusing on each participant's difficulties in lifestyle change. We requested all physicians to perform this intervention, even if the consultation duration exceeded the usual appointment time (Table 1).

In the control group, at the first consultation after randomization, participants were informed of their ideal body weight, weight reduction target, and positive effect of weight reduction, as in the intervention group.
Thereafter, participants received care for their current diseases based on the Japanese guidelines every 1 or 2 months. However, the physician was not required to measure body weight or discuss body weight reduction at every consultation.

\section{Outcomes}

The primary outcome of this study was change in body weight at 1-year follow up. Secondary outcomes were changes in body weight at 6-month follow up, and changes in abdominal circumference and blood pressure at the 6month and 1-year follow ups. Nurses blinded to the group assignment of each patient measured body weight, abdominal circumference, and blood pressure at 6 months and 1 year. The nurses then asked the participants about their frequency of weight self-monitoring at the 1-year follow up using the same classification as that used at baseline. Physicians recorded the length (in minutes and seconds) of each consultation and calculated the mean length for each patient after all participants had completed the 1-year follow up.

\section{Sample size calculation}

We selected a mean weight difference of $2 \mathrm{~kg}$ after 1 year as clinically significant and assumed a standard deviation of weight change of $2 \mathrm{~kg}$, in accordance with a previous study [34]. The present study was designed to have an $80 \%$ power to detect a weight change of $2 \mathrm{~kg}$ in

Table 1 Consultation content

\begin{tabular}{|c|c|c|}
\hline & Intervention group & Control group \\
\hline \multirow{4}{*}{$\begin{array}{l}\text { First consultation } \\
\text { after randomization }\end{array}$} & Explanations were given on the following: & Explanations were given on the following: \\
\hline & $\begin{array}{l}\text { Ideal body weight (body mass index, } 22 \mathrm{~kg} / \mathrm{m}^{2} \text { ) and weight } \\
\text { reduction target of each participant ( } 5 \% \text { body weight). }\end{array}$ & $\begin{array}{l}\text { Ideal body weight (body mass index, } 22 \mathrm{~kg} / \mathrm{m}^{2} \text { ) and weight } \\
\text { reduction target of each participant ( } 5 \% \text { body weight). }\end{array}$ \\
\hline & $\begin{array}{l}\text { The positive effect of weight reduction for the participant's } \\
\text { present disease. }\end{array}$ & $\begin{array}{l}\text { The positive effect of weight reduction for the participant's } \\
\text { present disease. }\end{array}$ \\
\hline & $\begin{array}{l}\text { A physician measured the participant's body weight and } \\
\text { provided specific advice on weight reduction at every } \\
\text { routine consultation. }\end{array}$ & \\
\hline \multirow[t]{8}{*}{$\begin{array}{l}\text { Every subsequent } \\
\text { routine consultation }\end{array}$} & $\begin{array}{l}\text { Routine consultations were performed every } 1 \text { or } 2 \text { months } \\
\text { for the participant's present disease based on the guidelines } \\
\text { for the disease. }\end{array}$ & $\begin{array}{l}\text { Routine consultations were performed every } 1 \text { or } 2 \text { months } \\
\text { for the participant's present disease based on the guidelines } \\
\text { for the disease. }\end{array}$ \\
\hline & Body weight was measured. & \\
\hline & $\begin{array}{l}\text { The physician questioned the patient on key lifestyle factors for } \\
\text { weight reduction (i.e., eating, exercising, and weight monitoring) }\end{array}$ & \\
\hline & $\begin{array}{l}\text { The physician provided information on the following standard } \\
\text { lifestyle changes for obese people: }\end{array}$ & \\
\hline & $\begin{array}{l}\text { Calorie intake (reduce calorie intake to } 25 \mathrm{kcal} / \mathrm{kg} \text { ideal body } \\
\text { weight/day). }\end{array}$ & \\
\hline & $\begin{array}{l}\text { Eat a well-balanced diet (calorie balance: protein, } 10-15 \% \text {; fat, } \\
20-25 \% \text {, and carbohydrate, } 60 \% \text { ). }\end{array}$ & \\
\hline & Exercise for 20-30 min at least three times per week. & \\
\hline & $\begin{array}{l}\text { The physician provided advice focusing on weight reduction } \\
\text { adjusted to each participant's circumstances and lifestyle. }\end{array}$ & \\
\hline
\end{tabular}


Table 2 Baseline demographic and clinical characteristics of participants

\begin{tabular}{|c|c|c|c|c|c|}
\hline & $n(\%)$ & interquartile rang & & & \\
\hline & Interve & & Control & & $p$ value \\
\hline & $n=29$ & & $n=21$ & & \\
\hline Age (years) & 56 & (38 to 65$)$ & 55 & (42 to 63 ) & 0.94 \\
\hline Sex & & & & & 0.39 \\
\hline Female & 9 & (31) & 9 & (43) & \\
\hline Male & 20 & (69) & 12 & (57) & \\
\hline Weight (kg) & 71.8 & $(67.3$ to 82.4$)$ & 74.1 & (68.1 to 77.4$)$ & 0.84 \\
\hline Height (cm) & 164.5 & (156.5 to 168.3 ) & 162.5 & (154.5 to 168.1$)$ & 0.79 \\
\hline $\mathrm{BMI}\left(\mathrm{kg} / \mathrm{m}^{2}\right)$ & 27.6 & (26.4 to 29.5$)$ & 27.6 & (26.9 to 28.4 ) & 0.78 \\
\hline Abdominal circumference $(\mathrm{cm})$ & 94.0 & (91.8 to 98.0$)$ & 95.0 & (92.0 to 97.5$)$ & 0.93 \\
\hline Blood pressure & & & & & \\
\hline Systolic blood pressure $(\mathrm{mmHg})$ & 130 & (120 to 140$)$ & 132 & (120 to 138$)$ & 0.85 \\
\hline Diastolic blood pressure $(\mathrm{mmHg})$ & 82 & (72 to 86$)$ & 78 & (71 to 86$)$ & 0.88 \\
\hline Serum lipid profile & & & & & \\
\hline Low-density lipoprotein (mg/dl) & 128 & (101 to 147$)$ & 126 & (103 to 148 ) & 0.86 \\
\hline High-density lipoprotein (mg/dl) & 56 & (45 to 61$)$ & 53 & (45 to 62$)$ & 0.85 \\
\hline Triglyceride (mg/dl) & 117 & (88 to 171 ) & 109 & (88 to 126$)$ & 0.52 \\
\hline Fasting blood sugar (mg/dl) & 100 & (95 to 109) & 102 & (95 to 117 ) & 0.42 \\
\hline Hemoglobin A1c (\%) & 5.5 & (5.2 to 5.9$)$ & 5.7 & (5.3 to 6.2$)$ & 0.15 \\
\hline Regular medication & & & & & \\
\hline Antihypertensive drug & 24 & (82) & 15 & (71) & 0.49 \\
\hline Lipid-lowering drug & 9 & (31) & 7 & (33) & 0.86 \\
\hline Anti-diabetic drug & 0 & (0) & 5 & (24) & 0.01 \\
\hline Medical history & & & & & \\
\hline Hypertension & 25 & (86) & 17 & (81) & 0.71 \\
\hline Dyslipidemia & 11 & (38) & 8 & (38) & 0.99 \\
\hline Type 2 diabetes mellitus & 2 & (7) & 6 & (29) & 0.06 \\
\hline Metabolic syndrome criteria & & & & & \\
\hline Japanese criteria & 15 & (52) & 6 & (29) & 0.10 \\
\hline NCEP-ATP III criteria & 15 & (52) & 7 & (33) & 0.20 \\
\hline Educational background & & & & & 0.48 \\
\hline Under high school & 7 & (24) & 7 & (33) & \\
\hline High school and above & 22 & (76) & 14 & (67) & \\
\hline Smoking & & & & & 0.87 \\
\hline Non-smoker & 24 & (83) & 17 & (81) & \\
\hline Currently smoker & 5 & (17) & 4 & (19) & \\
\hline Alcohol drinking & & & & & 0.53 \\
\hline Under once a week & 14 & (48) & 12 & (57) & \\
\hline Once a week or more & 15 & (52) & 9 & (43) & \\
\hline Weight self monitoring frequency ${ }^{a}$ & & & & & 0.73 \\
\hline Under once a week & 14 & (48) & 11 & (52) & \\
\hline Once a week or more & 14 & (48) & 9 & (43) & \\
\hline
\end{tabular}


Table 2 Baseline demographic and clinical characteristics of participants (Continued)

\begin{tabular}{lllll}
\hline Home blood pressure monitoring & & & \\
Regularly & 24 & (83) & 14 & (67) \\
Not regularly & 5 & (17) & 6 & (33) \\
\hline
\end{tabular}

We compared groups with the Mann-Whitney $U$ test or Chi-squared test

BMI, body mass index; NCEP-ATP, Cholesterol Education Program-Adult Treatment Pane

${ }^{a}$ Data were missing for one patient in the intervention group and one patient in the control group

both groups. For this purpose, at least 17 participants were needed in each group. We considered $\mathrm{p}<0.05$ as statistically significant.

\section{Blinding}

We informed the participants and the physicians, but not the nurses, of the randomization results at the first consultation after randomization. No measurement data were given to the physicians. Analysis was performed after all data had been collected.

\section{Statistical analyses}

Analysis was based on the intention-to-treat principle. The categorical variables of baseline data were converted into binary categories, education background ( $<$ high school or $\geq$ high school), history of smoking (nonsmoker or currently smoker), history of drinking alcohol (<once a week or $\geq$ once a week), and frequency of body weight self-monitoring (<once a week or $\geq$ once a week). We analyzed baseline data between the two participant groups using the Mann-Whitney $U$ test and Chi-squared test. The main outcome and secondary outcomes were analyzed using the Mann-Whitney $U$ test. Statistical analysis was performed using SPSS Statistics (version 17.0; SPSS Inc, Chicago, IL).

\section{Ancillary analyses}

Further analyses were conducted on the associations between body weight change and consultation factors. Data of 40 participants, regardless of their randomization group, who completed the 1-year follow up were used. We focused on the consultation factors, which included the number of consultations over 1 year, total length of consultations over the year, mean length of each consultation, and number of physicians who saw participants in the clinic over the year, in order to calculate the total consultation length over the year and the mean length of each consultation. The number of physicians who saw participants was obtained from the medical records. The associations of these factors with the change in body weight over the 1-year period were analyzed using Spearman's rank correlation coefficient.

In another ancillary analysis, we focused on the weight self-monitoring factors, which included their frequency and change over the 1-year period. From the self-reported weight self-monitoring frequency at baseline and at the 1-year follow up, we divided the participants into the following two groups based on change in weight selfmonitoring frequency: those with a decreased frequency (decreased group), and those with an increased or unchanged frequency (non-decreased group). We then analyzed the relationship between amount of body weight change at 1 year and the frequency, or change in the frequency, of weight self-monitoring over the year. Data were analyzed using the Kruskal-Wallis test and the Mann-Whitney $U$ test.

This study was approved by the Ethics Board of Fukushima Medical University (No. 905) and is registered in the UMIN Clinical Trial Registry (UMIN 000002967).

\section{Results}

For participants in both groups, the mean age (SD) was 54.8 (6.7) years, mean body weight (SD) was 74.1 (9.6) kg, and mean BMI (SD) was $28.1(2.1) \mathrm{kg} / \mathrm{m}^{2}$. At baseline, no significant differences were evident between the groups (Table 2). In one year follow-up period, 12 participants changed regular prescription drugs (Table 3 ). The median number of consultations (interquartile range [IQR]) was 8 (7 to 10) in the intervention group and 10 (9 to 11) in the control group. The median consultation length (IQR) for each patient over the 1-year period was 59.1 (51.4 to 71.1)

Table 3 Regular prescription drugs change between baseline and the 1-year follow up

\begin{tabular}{|c|c|c|c|c|}
\hline & \multicolumn{4}{|c|}{ Number of participants, n (\%) } \\
\hline & \multirow{2}{*}{\multicolumn{2}{|c|}{$\begin{array}{l}\text { Intervention group } \\
n=22\end{array}$}} & \multirow{2}{*}{\multicolumn{2}{|c|}{$\begin{array}{l}\text { Control group } \\
n=18\end{array}$}} \\
\hline & & & & \\
\hline \multicolumn{5}{|c|}{ Antihypertensive drugs } \\
\hline Increase & 1 & (5) & 5 & $(28)$ \\
\hline Stable & 21 & $(95)$ & 13 & $(72)$ \\
\hline Decrease & 0 & & 0 & \\
\hline \multicolumn{5}{|c|}{ Lipid-lowering drug } \\
\hline Increase & 3 & $(14)$ & 1 & (6) \\
\hline Stable & 19 & $(86)$ & 17 & $(94)$ \\
\hline Decrease & 0 & & 0 & \\
\hline \multicolumn{5}{|c|}{ Anti-diabetic } \\
\hline Increase & 0 & & 1 & $(6)$ \\
\hline Stable & 22 & $(100)$ & 16 & (88) \\
\hline Decrease & 0 & & 1 & (6) \\
\hline
\end{tabular}


Table 4 Consultation factors in the intervention and control groups

\begin{tabular}{|c|c|c|c|c|c|}
\hline \multirow{4}{*}{ Number of consultations in one year } & \multicolumn{5}{|c|}{ Median (interquartile range) } \\
\hline & \multirow{2}{*}{\multicolumn{2}{|c|}{$\begin{array}{l}\text { Intervention group } \\
n=22\end{array}$}} & \multirow{2}{*}{\multicolumn{2}{|c|}{$\begin{array}{l}\text { Control group } \\
\mathrm{n}=18\end{array}$}} & \multirow{3}{*}{$\begin{array}{l}p \text { value } \\
0.01^{*}\end{array}$} \\
\hline & & & & & \\
\hline & 8 & (7 to 10$)$ & 10 & (9 to 11$)$ & \\
\hline Total consultation duration in one year (min) & 59.1 & (51.4 to 71.1$)$ & 79.7 & (64.8 to 97.8$)$ & $0.002^{*}$ \\
\hline Average duration of consultation (min) & 7.0 & $(6.3$ to 8.0$)$ & 8.0 & (6.3 to 9.9$)$ & 0.13 \\
\hline
\end{tabular}

min in the intervention group and 79.7 (64.8 to 97.8) $\mathrm{min}$ in the control group. The median length (IQR) of each consultation was 7.0 (6.3 to 8) $\mathrm{min}$ in the intervention group and 8.0 (6.4 to 9.8) $\mathrm{min}$ in the control group. The median number of doctors (IQR) who saw each participant over the 1-year period was 2 ( 1 to 3 ) in the intervention group and 2 ( 1 to 3 ) in the control group. The number of consultations $(\mathrm{p}=0.01)$ and the total consultation length $(p=0.002)$ were significantly different in both groups. The length of each consultation was not significantly different $(\mathrm{p}=0.13)$ (Table 4$)$.

Intention-to-treat analysis revealed that at 1 year, 15 participants in the intervention group (68\% of the group) and 9 participants in control group (50\% of the group) had decreased their body weight from baseline values. The median (IQR) change in body weight from baseline was $-0.8(-2.5$ to 1.0$) \mathrm{kg}$ in the intervention group and $0.2(-2.4$ to 0.8$) \mathrm{kg}$ in the control group. There was no significant difference in this primary outcome $(\mathrm{p}=0.68)$ observed between the groups (Fig. 2).
No significant differences in secondary outcomes were noted between the groups; that is, the median (IQR) changes in the intervention and control groups at the 1-year follow up were $0.0(-3.5$ to 1.5$) \mathrm{cm}$ and -1.2 $(-2.8$ to 1.0$) \mathrm{cm}$ for abdominal circumference, 2 ( -12 to 10) $\mathrm{mmHg}$ and -1 (-10 to 7$) \mathrm{mmHg}$ for systolic blood pressure, and -2 (-6 to 4$) \mathrm{mmHg}$ and -2 (-10 to 8 ) $\mathrm{mmHg}$ for diastolic blood pressure, respectively. The median (IQR) changes in the intervention and control groups at 6 months were $-1.0(-2.3$ to 0.6$) \mathrm{kg}$ and -1.9 ( -3.8 to $0.6) \mathrm{kg}$ for body weight, $-1.1(-2.4$ to 0.9$) \mathrm{cm}$ and -2.8 ( -4.0 to -0.4$) \mathrm{cm}$ for abdominal circumference, 0 (-6 to 9) $\mathrm{mmHg}$ and 0 ( -15 to 7$) \mathrm{mmHg}$ for systolic blood pressure, and -1 ( -6 to 7$) \mathrm{mmHg}$ and -2 (-10 to 7$) \mathrm{mmHg}$ for diastolic blood pressure, respectively (Fig. 3). Again, no significant differences were observed between the groups.

\section{Ancillary analyses}

In analysis of consultation factors, the mean number of consultations (SD) was 9.1 (2.1), mean total consultation

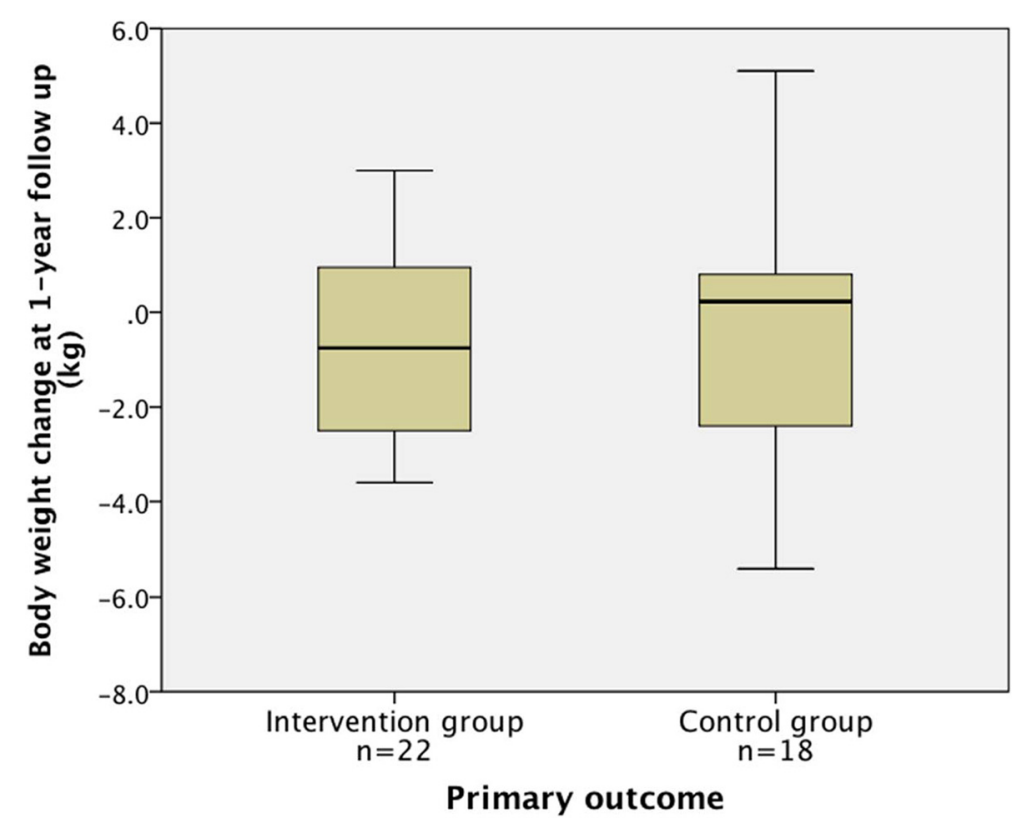

Fig. 2 Box plots of body weight change at the 1-year follow up 

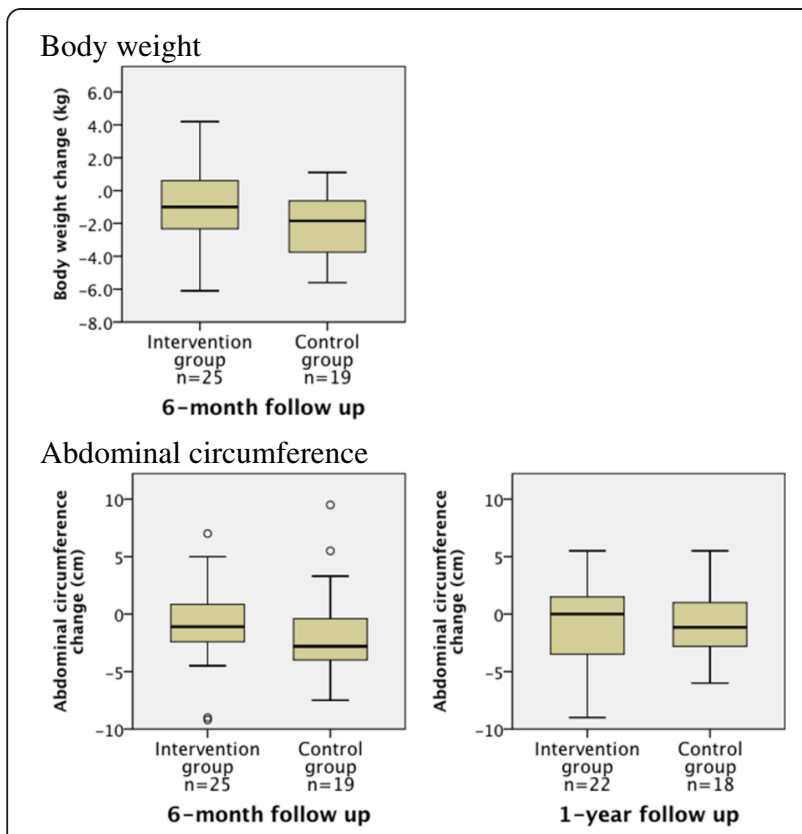

Systolic blood pressure
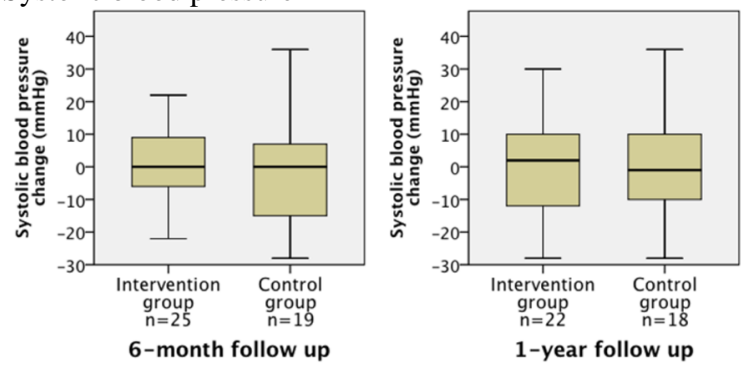

Diastolic blood pressure
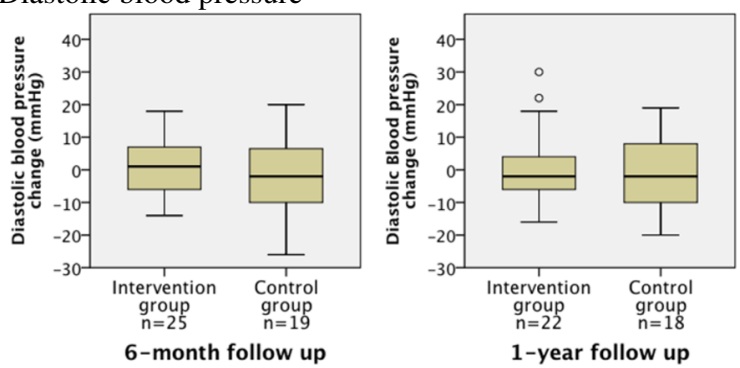

Fig. 3 Box plots of secondary outcomes

length (SD) over 1 year was 70.6 (24.9) min, mean length of each consultation (SD) was 7.8 (2.2) min, and mean number of physicians who saw each participant (SD) was 2.1 (1.0). The correlation coefficient was 0.16 ( $\mathrm{p}=$ 0.31 ) for body weight change and the number of consultations, $0.32(\mathrm{p}=0.05)$ for body weight change and the total consultation length, $0.30(p=0.06)$ for body weight change and length of each consultation, and -0.01 $(\mathrm{p}=0.93)$ for body weight change and the number of physicians who saw each participant. A weak positive correlation was seen between body weight change and total consultation length over the year.
In another ancillary analysis about body weight selfmonitoring, at baseline, weight self-monitoring was performed less than once a month by 13 (33\%) participants, less than once a week by $8(20 \%)$ participants, several times per week by 11 (28\%) participants, and daily by 8 (20\%) participants. The median (IQR) of body weight change at the 1-year follow up was -0.6 (-2.7 to 0.7$) \mathrm{kg}$ in participants self-monitoring less than once a month, -0.4 $(-2.2$ to 0.9$) \mathrm{kg}$ in those self-monitoring less than once a week, $-1.7(-2.9$ to 1.1$) \mathrm{kg}$ in those self-monitoring several times per week, and $-1.3(-2.7$ to 1.1$) \mathrm{kg}$ in those selfmonitoring daily (Fig. 4). Analysis using the Kruskal-Wallis test showed no significant differences $(p=0.86)$. We calculated the change in the frequency of weight selfmonitoring from baseline to the 1-year follow up (Table 5). Eight participants $(21 \%)$ had decreased their frequency of weight self-monitoring, 20 (54\%) showed no change, and 9 (24\%) had increased their frequency at the 1-year follow up. We analyzed body weight change over the 1-year period between the decreased group $(n=8)$ and the nondecreased group $(n=29)$. The median (IQR) changes in body weight between baseline and the 1-year follow up were $-1.8(-2.7$ to 0.6$) \mathrm{kg}$ in the non-decreased group and $0.9(-0.4$ to 1.8$) \mathrm{kg}$ in the decreased group, a significant difference $(p=0.009)$ between the groups (Fig. 5).

It should be noted that the study area was affected by the Great East Japan Earthquake in March 2011, which occurred during the study period. In the aftermath, both water and gasoline were in short supply, which forced some participants to evacuate to community halls for several days. The 1-year follow up for 11 participants of the intervention group (50\% of the group) and 9 in the control group (50\% of the group) (total 20; $50 \%$ ) was done after the earthquake, and we analyzed the effect of the earthquake on body weight change using the MannWhitney $U$ test (Table 6). No significant differences were observed in body weight change between the participants who attended the 1-year follow up before the earthquake and those who attended after it $(\mathrm{p}=0.95)$.

\section{Discussion}

We planned this study to reveal the effects on obese Japanese patients of adding a brief intervention for body weight reduction to routine consultations with a physician. We accomplish the randomized controlled trial at a family medicine clinic in the primary care setting. Given the lower incidence rate of severe obesity in Japan than in developed Western countries $[1,4]$, we need an intervention method that not only addresses severe obesity, but also overweight and moderate obesity. In this study, only 8 participants (16\%) were severely obese (BMI $\geq 30$, Japanese criteria), and the average BMI was 28.1, which is classed as moderately obese. 


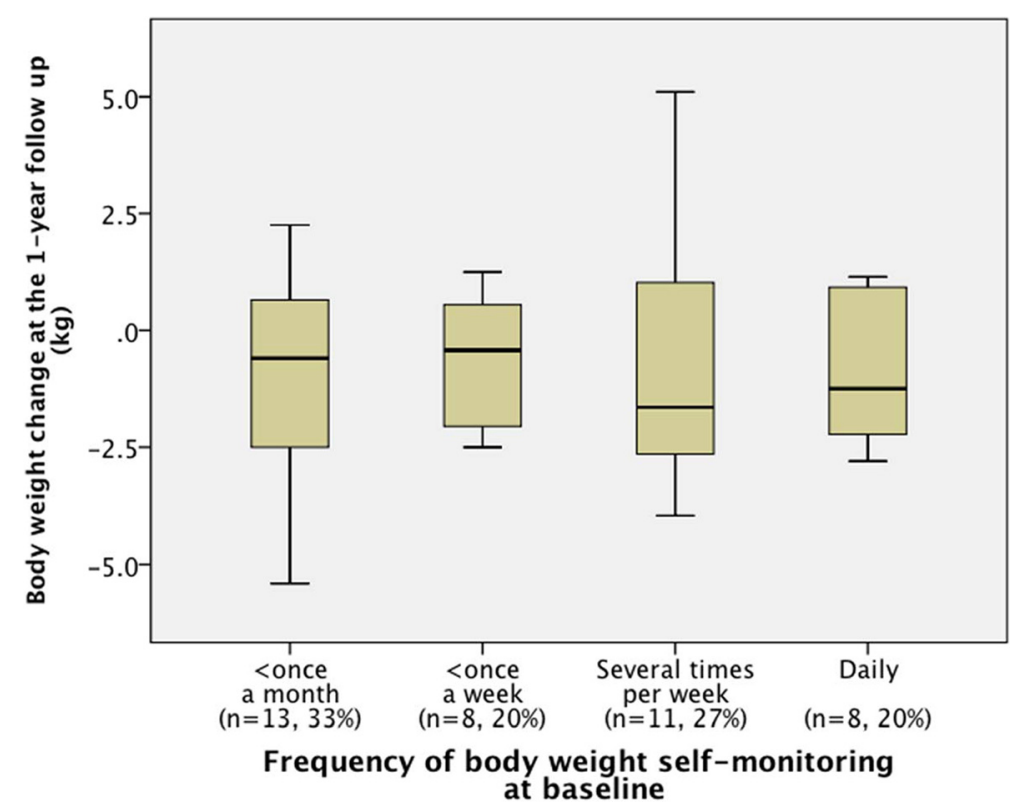

Fig. 4 Box plots of body weight change at the 1-year follow up in relation to the frequency of self-monitoring at baseline

Our results revealed no significant differences in consultation length between the intervention and control groups. This intervention method was performed briefly as planned and proved suitable for short routine consultations. It is noteworthy that the present intervention method is feasible for short routine consultations in the real-world clinical setting.

The total consultation length was unexpectedly longer in the control group than in the intervention group. The consultation length for the control group might have been longer because the control group had a higher ratio of participants who gained body weight. A possible explanation for this finding is that physicians may have extended the duration of each consultation for patients who gained weight and may have kept consultations short for patients who maintained or lost weight. Alternatively, physicians may have extended the consultation time in general to measure body weight and provide advice to patients in the intervention group within the short consultation time allotted and in doing so might have unintentionally overlooked other aspects of care while being preoccupied with the measurement, keeping the consultation time shorter for the intervention group overall.

Although we planned a brief and easy-to-perform intervention method for body weight reduction, no significant additional effects on usual care were observed. On the other hand, the result does not deny effect of all other simple low cost interventions. Brief advice provided by physicians has been effective for quitting smoking [35] in the primary care setting, and simple intervention methods used by primary care physicians to encourage patients to quit smoking have been established [36]. Weight reduction is more complex than smoking cessation in two regards. First, smoking is not essential to survival. Physicians, therefore, can provide clear advice to stop smoking. On the other hand, patients cannot simply stop eating. Physicians can, however, advise on how to eat. Quitting a behavior can be a simpler approach than finding an appropriate way to adjust a behavior. Second, is the nature of underlying

Table 5 Comparison of body weight self-monitoring frequency at baseline and at the 1-year follow up

\begin{tabular}{|c|c|c|c|c|c|c|c|c|c|c|c|}
\hline & & $\mathrm{Nu}$ & f partic & $n($ & & & & & & & \\
\hline & & & of bo & & nitorin & & bllow up & & & & \\
\hline & & $<0$ & honth & & week & & week & Da & & Tot & \\
\hline Frequency at Baseline & $<$ Once a month & 6 & (16) & 3 & (8) & 1 & (3) & 1 & (3) & 11 & $(29)$ \\
\hline & $<$ Once a week & 3 & (8) & 3 & (8) & 2 & (5) & 0 & (0) & 8 & $(22)$ \\
\hline & >Once a week & 2 & (5) & 2 & (5) & 5 & (14) & 2 & (5) & 11 & (29) \\
\hline & Daily & 0 & (0) & 1 & (3) & 0 & (0) & 6 & $(16)$ & 7 & (19) \\
\hline & Total & 11 & (30) & 9 & $(24)$ & 8 & (22) & 9 & (24) & 37 & $(100)$ \\
\hline
\end{tabular}




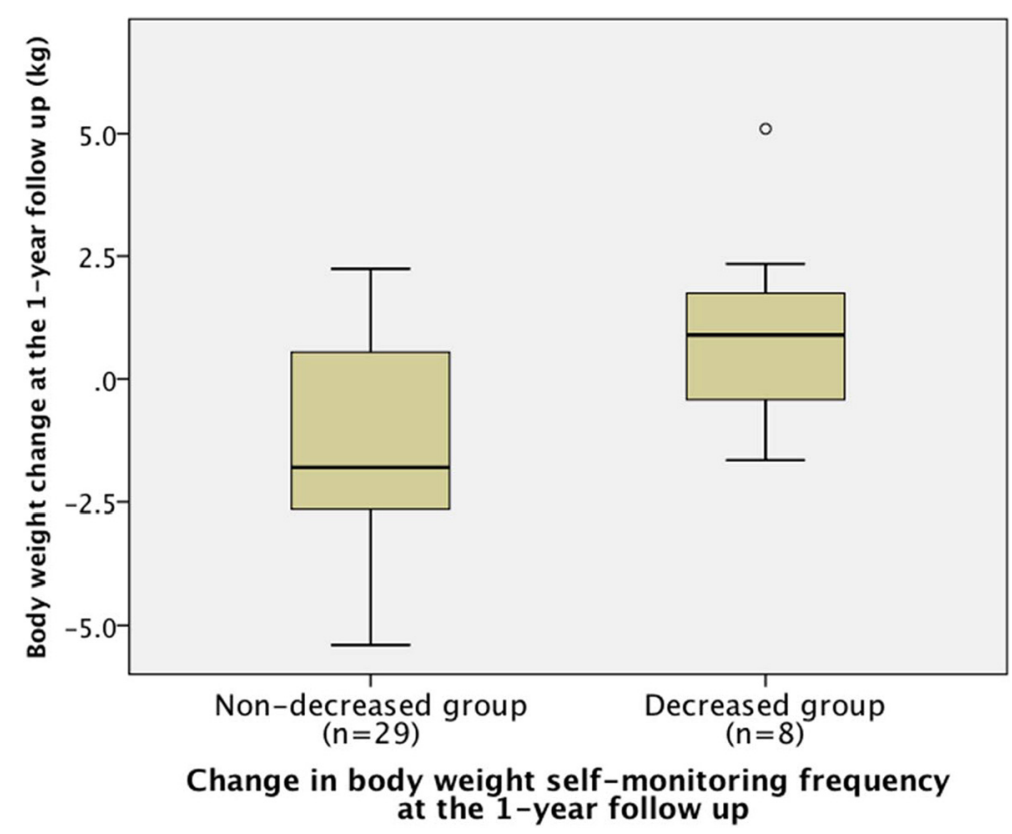

Fig. 5 Box plots of body weight change in 1-year follow up by body weight self-monitoring frequency

medical conditions. Since smoking is a behavioral risk factor for health, physicians can focus their advice directly on smoking behavior. On the other hand, obesity is a biomedical condition resulting from the interactions between social, behavioral, cultural, physiological, metabolic, and genetic factors [37]. To successfully reduce weight, obese patients need to change their eating, exercising, working, and other behaviors. Consequently, physicians need to intervene in multiple factors for weight reduction when dealing with obese patients.

Multiple categories of intervention for body weight reduction are available. The intervention method used in this study was based on a behavioral approach, for which we attached high value to an easy-to-perform method. Previous studies have shown that intervention methods involving multiple approaches for weight reduction are more effective than those with a single approach $[14,38,39]$. Thus, to develop an effective intervention method for reducing body weight during short, primary care consultations, it may be useful to encompass multiple brief and easy-to-perform approaches suited to short consultations.

The approach of our clinic may affect outcomes. As effective doctor-patient communication can improve patient health outcomes [24], family medicine trainees need to improve their skills in doctor-patient communication during residency training. The family medicine clinic, which served as a teaching clinic in the family medicine residency program, had four family physicians. One of the physicians was a faculty member and the other three were senior trainees of family medicine. In this case, more experienced family physicians could have made the difference in the intervention method.

As another consideration for devising a brief and easyto-perform intervention method, we noted weight selfmonitoring. In a previous study, Butryn and colleagues showed that more frequent body weight self-monitoring is related to body weight maintenance in patients who

Table 6 Comparison of weight change at the 1-year follow up between before and after the Great East Japan Earthquake

\begin{tabular}{|c|c|c|c|c|}
\hline & & & & Total \\
\hline & & Before the earthquake & After the earthquake & \\
\hline \multirow[t]{2}{*}{ Intervention group } & Number of participants & 9 & 9 & 18 \\
\hline & Weight change $(\mathrm{kg})^{\mathrm{a}}$ & $-0.4 \mathrm{~kg}$ & $-0.7 \mathrm{~kg}$ & $-0.5 \mathrm{~kg}$ \\
\hline \multirow[t]{2}{*}{ Control group } & Number of participants & 11 & 11 & 22 \\
\hline & Weight change $(\mathrm{kg})^{\mathrm{a}}$ & $-1.0 \mathrm{~kg}$ & $-0.6 \mathrm{~kg}$ & $-0.8 \mathrm{~kg}$ \\
\hline \multirow[t]{2}{*}{ Total } & Number of participants & 20 & 20 & 40 \\
\hline & Weight change $(\mathrm{kg})^{\mathrm{a}}$ & $-0.7 \mathrm{~kg}$ & $-0.6 \mathrm{~kg}$ & $-0.7 \mathrm{~kg}$ \\
\hline
\end{tabular}

${ }^{a}$ Mean weight change between baseline and the 1-year follow up 
had lost weight [40]. Some researchers have proposed that weight self-monitoring increases obese patients' awareness of their weight and results in them modifying their eating and exercise behavior [41]. The result of ancillary analysis revealed the relationship between self-monitoring frequency at baseline and body weight reduction, as well as that between change in body weight self-monitoring frequency and body weight reduction. We, therefore, consider it worthwhile to explore this relationship further in a future prospective study.

This study has several limitations. First, it was conducted at a single family medicine clinic, where it was difficult to analyze subjects by sex, age, and other factors due to the number of eligible patients. If the number of participants had been larger, we might detect modest weight reduction. And if the observation period had been longer, we might detect long-term weight change. In real primary care setting, even if effect sizes are small, simple low-cost intervention methods can be used without too much difficulty for years and, therefore, they are of benefit to the patients. A cluster randomized controlled multicenter design is a possible solution for assembling more participants and acquiring more evidence with greater power. The second limitation is that this study was conducted in the Japanese clinical setting, which differs from that in Western countries in terms of shorter and more frequent consultations. The third limitation is that the intervention method was affected by doctor-patient communication as we did not strictly standardize the weight reduction advice provided by the physicians. This might have resulted in inter-physician differences in the intervention, which were not measured. If we had evaluated doctor-patient communication, we would have been able to take variables of patients' viewpoint. The fourth limitation is that this study did not have data about diet and exercise. We could not analyze about food choice and other actions of the participants. A final limitation is the effects of the Great East Japan Earthquake. In particular, we could not eliminate the effects of the earthquake because of the small study population.

\section{Conclusions}

We studied the intervention method used by physicians to measure body weight and advise patients on weight reduction during routine consultations. In our setting, this method did not extend the consultation duration, but also had no significant effects on body weight reduction in moderately obese patients. Therefore, additional studies on simple and easy-to-perform intervention methods are needed. Taken together, the present findings revealed a potential research question on the relationship between weight self-monitoring and body weight reduction in the primary care setting.

\section{Competing interests}

Part of this study was financially supported by the Jinsenkai Public Interest Incorporated Foundation.

\section{Authors' contributions}

SK designed this study, analyzed data, and drafted the manuscript. TK participated in the analyses and drafted the manuscript. NT and YM carried out participants' intervention. Al carried out randomization of participants. RK supervised all the study process and reviewed the manuscript. All authors read and approved the final manuscript.

\section{Acknowledgement}

We thank Kimie lizuka, Tomoko Yoshida, and Emiko Furukawa for their assistance in measuring patient parameters. We are also grateful to all the participants in this study.

\section{Author details}

'Department of Community and Family Medicine, Fukushima Medical University, 1 Hikarigaoka, Fukushima City, Fukushima Prefecture, Japan. ${ }^{2}$ Department of Internal Medicine, Kashima Hospital, 22-1 Shimokuramochi Nakasawame, Kashima-machi, Iwaki City, Fukushima Prefecture, Japan.

Received: 10 October 2014 Accepted: 12 May 2015

Published online: 21 May 2015

\section{References}

1. Ministry of Health, Labour and Welfare, Japan: 2011 Patient survey. http://www.mhlw.go.jp/english/database/db-hss/sps_2011.html. Accessed 13 Nov 2013

2. Mokdad AH, Ford ES, Bowman BA, Dietz WH, Vinicor F, Bales VS, et al. Prevalence of obesity, diabetes, and obesity-related health risk factors, 2001. JAMA. 2003;289:76-9.

3. Xiao J, Yang W. Weight loss is still an essential intervention in obesity and its complications: a review. J Obes. 2012;2012:1-6.

4. World Health Organization. Obesity and overweight WHO fact sheet No311. 2013.

5. Ministry of Health, Labour and Welfare, Japan: 2011 National Health and Nutrition Survey. http://www.mhlw.go.jp/bunya/kenkou/kenkou_eiyou_ chousa.html. Accessed 11 Nov 2013. [in Japanese]

6. Kanazawa M, Yoshiike N, Osaka T, Numba Y, Zimmet P, Inoue S. Criteria and classification of obesity in Japan and Asia-Oceania. Asia Pac J Clin Nutr. 2002;11 Suppl 8:S732-7.

7. World Health Organization. Appropriate body-mass index for Asian populations and its implications for policy and intervention strategies. Lancet. 2004;363:157-63.

8. Jensen MD, Ryan DH, Apovian CM, Ard JD, Comuzzie AG, Donato KA, et al. 2013 AHA/ACC/TOS Guideline for the Management of Overweight and Obesity in Adults: A Report of the American College of Cardiology/American Heart Association Task Force on Practice Guidelines and The Obesity Society. Circulation. 2014;129(25 Suppl 2):S102-38. doi:10.1161/01.cir.0000437739.71477.ee. Epub 2013 Nov 12.5102-38.

9. Galuska DA, Will JC, Serdula MK, Ford ES. Are health care professionals advising obese patients to lose weight? JAMA. 1999;282:1576-8.

10. Stecker T, Sparks S. Prevalence of obese patients in a primary care setting. Obesity (Silver Spring). 2006:14:373-6.

11. Epstein L, Ogden J. A qualitative study of GPs' views of treating obesity. Br J Gen Pract. 2005;55:750-4.

12. Beasley JW. How many problems do family physicians manage at each encounter? A WReN study. Ann Fam Med. 2004;2:405-10.

13. Wadden TA, Volger S, Sarwer DB, Vetter ML, Tsai AG, Berkowitz Rl, et al. A two-year randomized trial of obesity treatment in primary care practice. $\mathrm{N}$ Engl J Med. 2011;365:1969-79.

14. Nanchahal K, Townsend J, Letley L, Haslam D, Wellings K, Haines A. Weight-management interventions in primary care: a pilot randomised controlled trial. Br J Gen Pract. 2009;59:157-66.

15. ter Bogt NCW, Bemelmans WJE, Beltman FW, Broer J, Smit AJ, van der Meer K Preventing weight gain by lifestyle intervention in a general practice setting: three-year results of a randomized controlled trial. Arch Intern Med. 2011;171:306-13. 
16. Bennett GG, Herring SJ, Puleo E, Stein EK, Emmons KM, Gillman MW. Web-based weight loss in primary care: a randomized controlled trial. Obesity. 2009;18:308-13.

17. Appel LJ, Clark JM, Yeh H-C, Wang N-Y, Coughlin JW, Daumit G, et al. Comparative effectiveness of weight-loss interventions in clinical practice. N Engl J Med. 2011:365:1959-68.

18. Suzuka T. The needs assessment of nutrition counseling in primary internal medicine clinic. Kyoto Igakukai Zassi. 2008;55:173-6 [in Japanese]

19. Christian JG, Bessesen DH, Byers TE, Christian KK, Goldstein MG, Bock BC. Clinic-based support to help overweight patients with type 2 diabetes increase physical activity and lose weight. Arch Intern Med. 2008;168:141-6.

20. Martin PD, Dutton GR, Rhode PC, Horswell RL, Ryan DH, Brantley PJ. Weight loss maintenance following a primary care intervention for low-income minority women. Obesity. 2012;16:2462-7.

21. Wooldridge AN, Arató N, Sen A, Amenomori M, Fetters MD. Truth or fallacy? Three hour wait for threeminutes with the doctor: findings from a privateclinic in rural Japan. Asia Pac Fam Med. 2010;9:11. doi:10.1186/s12930-014-0011-2.

22. Butryn ML, Webb V, Wadden TA. Behavioral treatment of obesity. Psychiatr Clin North Am. 2011;34:841-59.

23. German PS. Compliance and chronic disease. Hypertension. 1988;11:1156-60.

24. Stewart MA. Effective physician-patient communication and health outcomes: a review. CMAJ. 1995;152:1423-33.

25. Serretti A, Mandelli L. Antidepressants and body weight. J Clin Psychiatry. 2010;71:1259-72

26. Vanina Y, Podolskaya A, Sedky K, Shahab H, Siddiqui A, Munshi F, et al. Body weight changes associated with psychopharmacology. Psychiatr Serv. 2002;53:842-7.

27. Espeland MA, Stefanick ML, Kritz-Silverstein D, Fineberg SE, Waclawiw MA, James MK, et al. Effect of postmenopausal hormone therapy on body weight and waist and hip girths. Postmenopausal EstrogenProgestin Interventions Study Investigators. J Clin Endocrinol Metab. 1997:82:1549-56

28. Committee to Evaluate Diagnostic Standards for Metabolic Syndrome. Definition and the diagnostic standard for metabolic syndrome-Committee to Evaluate Diagnostic Standards for Metabolic Syndrome. Nippon Naika Gakkai Zasshi. 2005;94:794-809. in Japanese.

29. Grundy SM. Diagnosis and management of the metabolic syndrome: an American heart association/national heart, lung, and blood institute scientific statement. Circulation. 2005;112:2735-52.

30. Japan Society for the Study of Obesity. Obesity disease treatment guideline 2006. Himan Kenkyu. 2006;12(suppl):1-91. in Japanese.

31. Ogihara T, Kikuchi K, Matsuoka H, Fujita T, Higaki J, Horiuchi M, et al. The Japanese society of hypertension guidelines for the management of hypertension (JSH. Hypertens Res. 2009;2009:3-107.

32. Japan Atherosclerosis Society. Japan Atherosclerosis Society (JAS) Guidelines for Prevention of Atherosclerotic Cardiovascular Disease 2007. Tokyo: Kyowa Kikaku; 2007. in Japanese.

33. The Japan Diabetes Society. Evidence-based practice guideline for the treatment of diabetes in Japan 2010. Tokyo: Nankodo; 2010. in Japanese.

34. Tsai AG, Wadden TA, Rogers MA, Day SC, Moore RH, Islam BJ. A primary care intervention for weight loss: results of a randomized controlled pilot study. Obesity. 2009;18:1614-8.

35. Stead LF, Buitrago D, Preciado N, Sanchez G, Hartmann-Boyce J, Lancaster T. Physician advice for smoking cessation. Cochrane Database Syst Rev. 2013;5:CD000165.

36. US Department of Health and Human Services Tobacco Use and Dependence Guideline Panel: Treating Tobacco Use and Dependence: 2008 update. http://www.ahrq.gov/professionals/clinicians-providers/ guidelinesrecommendations/tobacco/clinicians/update/ treating_tobacco_use08.pdf. Accessed 5 Jan 2014

37. NHLBI Obesity Education Initiative Expert Panel on the Identification, Evaluation, and Treatment of Obesity in Adults: Clinical Guidelines on the Identification, Evaluation, and Treatment of Overweight and Obesity in Adults. Bethesda; 1998

38. Jakicic JM, Tate DF, Lang W, Davis KK, Polzien K, Rickman AD, et al. Effect of a stepped-care intervention approach on weight loss in adults: a randomized clinical trial. JAMA. 2012;307:2617-26.
39. Wu T, Gao X, Chen M, van Dam RM. Long-term effectiveness of diet-plus-exercise interventions vs. diet-only interventions for weight loss: a meta-analysis. Obes Rev. 2009;10:313-23.

40. Butryn ML, Phelan S, Hill JO, Wing RR. Consistent self-monitoring of weight: a key component of successful weight loss maintenance. Obesity. 2007;15:3091-6.

41. Burke LE, Wang J, Sevick MA. Self-monitoring in weight loss: a systematic review of the literature. J Am Diet Assoc. 2011;111:92-102.

\section{Submit your next manuscript to BioMed Central and take full advantage of:}

- Convenient online submission

- Thorough peer review

- No space constraints or color figure charges

- Immediate publication on acceptance

- Inclusion in PubMed, CAS, Scopus and Google Scholar

- Research which is freely available for redistribution

Submit your manuscript at www.biomedcentral.com/submit 